\title{
Chemistry Learning Anxiety Scale: A Scale Development
}

\author{
Widya Pangestika ${ }^{1, *}$ Antuni Wiyarsi ${ }^{2}$ \\ ${ }^{1}$ Master of Chemistry Education, Faculty of Mathematics and Natural Sciences, Universitas Negeri Yogyakarta, \\ Indonesia \\ ${ }^{2}$ Department of Chemistry Education, Faculty of Mathematics and Natural Sciences, Universitas Negeri \\ Yogyakarta, Indonesia \\ *Corresponding author. Email: widya0355pasca.2018@student.uny.ac.id
}

\begin{abstract}
The main purpose of the study was to develop the Chemistry Learning Anxiety Scale (CLAS) instrument. The method used this study is the survey method. Data of chemistry learning anxiety was obtained through a questionnaire. There are three aspects of the chemistry learning anxiety scale that were examined in this study, Anxiety in Study Chemistry, Anxiety in Finishing Chemistry Tasks, and Anxiety in Doing Practicum. The content validity of the CLAS instrument with 48 items that had been administered to 115 student's $11^{\text {th }}$ senior high school. The data were analyzed using the Rasch model that have been 5 criteria, namely unidimensionality, item fit, difficult/ability estimation, reliable, and information function. The conclusion of the Rasch model showed that there are 46 items CLAS that fit model and excellent reliable for the person's reliable and excellent reliable for the item reliable. The CLAS instrument is a good instrument to collect the data.
\end{abstract}

Keywords: Chemistry learning anxiety scale, Anxiety in study chemistry, Anxiety in finishing chemistry, Anxiety in doing practicum

\section{INTRODUCTION}

Chemistry is a branch of science, as said by [1] science is a body of knowledge which means it is the center of all knowledge. Besides, chemistry is one of the important subjects in high school and is closely dependent on various disciplines, such as pharmacy, medicine, technology, chemical technology, textile technology, and so on. However, most students consider chemistry to be a very difficult subject to answer and understand. This is consistent with research conducted by [2] that chemistry is an abstract subject, full of scientific concepts and students find it difficult to connect between microscopic and macroscopic chemistry [3]. Research conducted by [4] states that the factors that cause chemistry are difficult to do based on numeracy skills, classes that are too crowded, students' language skills in understanding chemistry, and teaching skills in teaching. As a result, students have a negative perspective on chemistry.

A student who has a negative perspective on chemistry will feel bored, anxious [5], afraid and insecure during the learning process [6] so that events of stress, worry, as excessive fear, and anxiety when studying chemistry are also called study chemistry. Packaging according to [7] is the basic emotion that a person has that happens at one time and is worried about something that is not certain to happen. However, a crisis is a feeling that someone does not want because it will interfere with the scientific process within a person [8].

Chemistry learning anxiety is caused by several factors expressed by [9] namely: the anxiety of learning chemistry when solving mathematical problems, tests, or evaluations, chemistry teachers who teach do not understand chemical content, work in chemical laboratories, and students' negative perceptions. when you hear the word "chemistry". Based on research conducted by [10] - [13] stated the anxiety of learning chemistry caused by three factors namely: studying chemistry, evaluating chemistry, and handling chemicals. [14] states the basic cause of anxiety when studying chemistry is the broad scope of the syllabus, low awareness of career opportunities in chemistry, lack of work visits to the field, incomplete laboratory equipment, and poor 
teaching methods. Based on the results of the research that has been done, the evaluation of chemistry learning hurts students, such as decreased academic achievement and academic performance, students' learning in receiving chemistry lessons [11] decreased learning motivation [4] and students cannot think clearly [15]. The chemistry learning instrument was first developed by [9] which aims to reduce chemistry learning consists of 6 items. Subsequently, [10] developed Chemistry learning anxiety consists of 36 items and is divided into 3 aspects, namely; learning, evaluation, and practicum. Meanwhile, this article aims to develop students' chemistry learning instruments.

\section{RESEARCH METHODS}

This study used a survey method. The sample involved was $11^{\text {th }}$ Senior High School, SMA Negeri 1 Godean, Yogyakarta, Indonesia.

\subsection{Development of Chemistry Learning Anxiety}

The instrument used in this study was developed based on the elaboration and adaptation of several researchers [5], [9], [10], [14], [15]. To confirm the validity of the content, the researchers outlined a framework theory about the chemistry learning anxiety scale as a basis for building items and ascertaining it to experts. The statements of the instrument are developed appropriately for students and then translated into Indonesian.

There are three dimensions of chemistry learning anxiety scale that were examined in this study, anxiety in study chemistry, anxiety in finishing chemistry tasks, and anxiety in doing a practicum. The response scale for the Chemistry Learning Anxiety Scale (CLAS) ranges from "High anxiety = 5 " to "No Anxiety = 1". Besides theoretical validity is done by asking for improvement in terms of language in the form of an assessment of the items of the instrument to two experts' lecturer from the Department of Chemistry Education. Empirical validity was done by giving questionnaires to 115 students.

\subsection{Data Analysis}

The results of validate the instrument and measure its reliability using the Rasch model by Winstep program. There are five characteristics for the analysis of instrument by unidimensionality, item fit, difficult/ability estimation, reliable, and information function.

\section{RESULT AND DISCUSSION}

\subsection{Unidimensionality}

The unidimensional assumption test aims to measure the items of a test measuring only one ability [16]. The unidimensional assumption test of an instrument can be done with factor analysis, namely Confirmatory factor analysis (CFA) which aims to identify whether the indicators used are the constructs of the research variables used or whether these indicators are unitary or unidimensional.

Furthermore, to ascertain whether a data is suitable or feasible can be done by confirmatory factor analysis, it is necessary to analyze the adequacy of the sample (data) by taking into account the KMO (Kaiser-Meyer-Olkin) value and the Barlett value. The accepted value requirements for factor analysis are $>0.6$ for the KMO value (Kaiser-MeyerOlkin) and Barlett's Test significance value which is smaller than 0.5 [17].

Table 1. KMO-MSA and barlettsphericity test results

\begin{tabular}{|l|l|l|}
\hline The Test & $\begin{array}{l}\text { Chemistry } \\
\text { Learning } \\
\text { Anxiety Scale }\end{array}$ & $\begin{array}{l}\text { Result for } \\
\text { Factor } \\
\text { Analysis }\end{array}$ \\
\hline KMO-MSA & 0.780 & Appropriate \\
\hline $\begin{array}{l}\text { The significant } \\
\text { value of Barlett- } \\
\text { sphericity test }\end{array}$ & 0.000 & Appropriate \\
\hline
\end{tabular}

The results from Table 1 show that, the output value of KMO-MSA and Barlettsphericity test is used to determine the feasibility of a variable. As for the criteria for the KMO-MSA value, if the KMO-MSA value is greater than 0,5 then the factor analysis can be continued. Based on the output Table 1, the KMOMSA value is 0.780 , and Barlett's test of sphericity (sig) $0,000<0,05$, then the factor analysis on unidimensionality or construct validity. Further analysis to test unidimensional assumptions is to test the eigenvalues of the inter-grain covariance variance matrix. This assumption is fulfilled if the percentage value of the matrix eigenvalues is more than $20 \%$ of the variance [18] or the total value obtained is greater than 1 [19]. The eigenvalues for the chemistry learning anxiety instrument are shown in Table 2.

Table 2 shows that the chemistry learning anxiety scale instrument can contain 13 eigenvalues which have a total eigenvalue greater than 1 . These results indicate that there are 13 factors formed that can explain 70,824 variances. 
Table 2. Total variance explained by the result of factor analysis

\begin{tabular}{|c|c|c|c|c|c|c|c|}
\hline \multirow[b]{2}{*}{ Factor } & \multicolumn{3}{|c|}{ Initian Eigen Value } & \multirow[b]{2}{*}{ Factor } & \multicolumn{3}{|c|}{ Initian Eigen Value } \\
\hline & Total & $\%$ of Variance & Cumulative & & Total & $\begin{array}{c}\% \text { of } \\
\text { Variance }\end{array}$ & Cumulative \\
\hline 1 & 12.766 & 26.596 & 26.596 & 25 & 0.481 & 1.002 & 88.481 \\
\hline 2 & 4.189 & 8.726 & 35.323 & 26 & 0.476 & 0.991 & 89.472 \\
\hline 3 & 2.539 & 5.290 & 40.613 & 27 & 0.424 & 0.882 & 90.354 \\
\hline 4 & 2.042 & 4.254 & 44.867 & 28 & 0.416 & 0.886 & 91.220 \\
\hline 5 & $\begin{array}{ll}1.07 L \\
1.780\end{array}$ & 3.708 & 48.575 & 29 & 0.383 & 0.798 & 92.018 \\
\hline 6 & 1.695 & 3.531 & 52.106 & 30 & 0.380 & 0.792 & 92.810 \\
\hline 7 & 1.586 & 3.304 & 55.410 & 31 & 0.361 & 0.751 & 93.561 \\
\hline 8 & 1.397 & 2.911 & 58.321 & 32 & 0.350 & 0.728 & 94.289 \\
\hline 9 & 1.362 & 2.837 & 61.159 & 33 & 0.314 & 0.654 & 94.943 \\
\hline 10 & 1.231 & 2.566 & 63.724 & 34 & 0.275 & 0.573 & 95.516 \\
\hline 11 & 1.210 & 2.521 & 66.245 & 35 & 0.268 & 0.559 & 96.075 \\
\hline 12 & 1.132 & 2.359 & 68.604 & 36 & 0.231 & 0.481 & 96.556 \\
\hline 13 & 1.066 & 2.220 & 70.824 & 37 & 0.224 & 0.467 & 97.023 \\
\hline 14 & 0.963 & 2.006 & 72.830 & 38 & 0.218 & 0.454 & 97.447 \\
\hline 15 & 0.953 & 1.985 & 74.815 & 39 & 0.191 & 0.397 & 97.874 \\
\hline 16 & 0.842 & 1.754 & 76.569 & 40 & 0.177 & 0.368 & 98.242 \\
\hline 17 & 0.801 & 1.669 & 78.238 & 41 & 0.159 & 0.331 & 98.573 \\
\hline 18 & 0.758 & 1.580 & 79.818 & 42 & 0.132 & 0.274 & 98.874 \\
\hline 19 & 0.698 & 1.454 & 81.272 & 43 & 0.122 & 0.254 & 99.101 \\
\hline 20 & 0.661 & 1.376 & 82.649 & 44 & 0.115 & 0.239 & 99.340 \\
\hline 21 & 0.632 & 1.317 & 83.966 & 45 & 0.095 & 0.198 & 99.538 \\
\hline 22 & 0.626 & 1.305 & 85.271 & 46 & 0.078 & 0.162 & 99.701 \\
\hline 23 & 0.546 & 1.138 & 86.409 & 47 & 0.074 & 0.153 & 99.854 \\
\hline 24 & 0.513 & 1.070 & 87.479 & 48 & 0.070 & 0.146 & 100.000 \\
\hline
\end{tabular}
eigenvalue with the number of components that can be maintained as a factor. The graph on the screen plot aims to visually describe the number of factors that are formed. Meanwhile, the scree plot of the total eigenvalues for the chemistry learning anxiety instrument can be seen in Figure 1. Based on Figure 1 , the scree plot can be observed that the relative curve starts to slope at factor 15 .

This shows that there are 13 factors formed where the first factor can explain the variance of more than $26.596 \%$, so the assumption unidimensional has been met [18]. The results of the local independence assumption test were carried out to complete a matrix divided into high to low levels using a variancecovariance matrix. In Table 3, shows that the covariance value of the participants shows 0.00 so that local independence can be fulfilled [20]. The zero value indicates that chemistry learning anxiety

Table 3. Covariance matrix of chemistry learning anxiety scale

\begin{tabular}{|c|c|c|c|c|c|c|c|c|c|c|}
\hline Columns & C1 & C2 & C3 & C4 & C5 & C6 & C7 & C8 & C9 & C10 \\
\hline C1 & $\begin{array}{c}0.026 \\
893\end{array}$ & & & & & & & & & \\
\hline C2 & $\begin{array}{l}0.010 \\
54\end{array}$ & $\begin{array}{l}0.004 \\
498\end{array}$ & & & & & & & & \\
\hline C3 & $\begin{array}{l}0.010 \\
473\end{array}$ & $\begin{array}{l}0.004 \\
2\end{array}$ & $\begin{array}{l}0.004 \\
582\end{array}$ & & & & & & & \\
\hline C4 & 0.008 & 0.003 & 0.003 & 0.0033 & & & & & & \\
\hline
\end{tabular}




\begin{tabular}{|l|l|l|l|l|l|l|l|l|l|l|}
\hline & 615 & 593 & 355 & 16 & & & & & & \\
\hline C5 & 0.005 & 0.002 & 0.001 & 0.0015 & 0.0010 & & & & & \\
& 114 & 001 & 991 & 54 & 51 & & & & & \\
\hline C6 & 0.007 & 0.003 & 0.003 & 0.0026 & 0.0014 & 0.0024 & & & & \\
& 612 & 034 & 164 & 12 & 46 & 07 & & & & \\
\hline C7 & 0.011 & 0.004 & 0.004 & 0.0034 & 0.0021 & 0.0030 & 0.0052 & & & \\
& 079 & 577 & 5 & 41 & 29 & 68 & 99 & & & \\
\hline C8 & 0.019 & 0.007 & 0.007 & 0.0056 & 0.0038 & 0.0051 & 0.0088 & 0.0162 & & \\
& 275 & 905 & 773 & 77 & 71 & 78 & 37 & 81 & & \\
\hline C9 & 0.033 & 0.013 & 0.013 & 0.0120 & 0.0062 & 0.0100 & 0.0140 & 0.0236 & 0.0459 & \\
& 622 & 863 & 745 & 28 & 12 & 72 & 53 & 74 & 6 & \\
\hline C10 & 0.076 & 0.025 & 0.044 & 0.0104 & 0.0122 & 0.0165 & 0.0411 & 0.0715 & 0.0812 & 0.9276 \\
& 7 & 961 & 183 & 83 & 22 & 94 & 5 & 11 & 33 & 22 \\
\hline
\end{tabular}

\subsection{Item Fit}

In the Rasch model concept, items that can be used to see the quality of an instrument are sufficient. Item analysis is used to see an item that can function normally in taking measurements or not. The item said is said to be valid, if it meets the requirements for data collection, at least 2 criteria. The criterion values used to check the suitability of the items were: (a) Means-square outfit value: $0.5<$ Means-square < 1.5; (b) Z-standard Outfit value: $-2.0<\mathrm{Z}$-standard < +2.0; (c) Point-Measure Correlation value: $0.4<$ Point- measure correlation $<0.85$ [21].

\subsection{Difficult/ Ability Estimation}

The level of difficult/ ability estimation is used to see the ability of participants to answer items correctly. Difficult level/ ability estimation criteria based on [19] if values of $b$ (item measure) $\leq-1$ indicate very easy; indicate easy $-.5 \leq \mathrm{b}<-1$; indicate medium -.5 $\leq \mathrm{b}<.5 ;<1$ indicate a very difficult; $.5 \leq \mathrm{b}<1$ indicate difficult; and $\mathrm{b}>1$ indicate very difficult.

Based on Table 4, all items that have been analyzed using the winstep program, 2 items are not fit, namely items 19 and 46. The result of the analysis showed 46 items are fitted with the PCM-1PL model can be used for the analysis of measuring chemistry learning anxiety students.

Table 4. The results of the fit measurement instrument test

\begin{tabular}{|l|l|l|l|l|l|l|l|l|l|}
\hline Item & $\begin{array}{l}\text { Means- } \\
\text { square } \\
\text { Outfit }\end{array}$ & $\begin{array}{l}\text { Z- } \\
\text { standard } \\
\text { Outfit }\end{array}$ & $\begin{array}{l}\text { Point- } \\
\text { Measure } \\
\text { Correlation }\end{array}$ & Result & Item & $\begin{array}{l}\text { Means- } \\
\text { square } \\
\text { Outfit }\end{array}$ & $\begin{array}{l}\text { Z- } \\
\text { standard } \\
\text { Outfit }\end{array}$ & $\begin{array}{l}\text { Point- } \\
\text { Measure } \\
\text { Correlation }\end{array}$ & Result \\
\hline 29 & 1.79 & 3.7 & 0.39 & Not fit & 14 & 1.05 & 0.4 & 0.38 & Fit \\
\hline 46 & 1.69 & 2.4 & 0.31 & Not fit & 12 & 0.96 & -0.2 & 0.51 & Fit \\
\hline 28 & 1.29 & 1.3 & 0.41 & Fit & 21 & 0.94 & -0.3 & 0.51 & Fit \\
\hline 1 & 1.19 & 1.0 & 0.42 & Fit & 40 & 0.99 & 0.0 & 0.55 & Fit \\
\hline 37 & 0.89 & -0.1 & 0.22 & Fit & 34 & 0.98 & -0.1 & 0.58 & Fit \\
\hline 30 & 1.29 & 1.8 & 0.39 & Fit & 19 & 0.97 & -0.1 & 0.44 & Fit \\
\hline 36 & 1.26 & 1.6 & 0.38 & Fit & 2 & 0.90 & -0.5 & 0.49 & Fit \\
\hline 24 & 1.26 & 1.8 & 0.53 & Fit & 31 & 0.98 & 0.0 & 0.46 & Fit \\
\hline 32 & 1.26 & 1.3 & 0.34 & Fit & 38 & 0.99 & 0.0 & 0.54 & Fit \\
\hline 20 & 1.21 & 1.6 & 0.52 & Fit & 41 & 0.98 & -0.1 & 0.44 & Fit \\
\hline 10 & 1.21 & 1.4 & 0.53 & Fit & 26 & 0.92 & -0.6 & 0.57 & Fit \\
\hline 35 & 1.17 & 1.3 & 0.44 & Fit & 11 & 0.93 & -0.4 & 0.54 & Fit \\
\hline 25 & 1.12 & 0.9 & 0.56 & Fit & 47 & 0.91 & -0.6 & 0.54 & Fit \\
\hline 23 & 1.11 & 0.9 & 0.56 & Fit & 22 & 0.89 & -0.8 & 0.63 & Fit \\
\hline 42 & 1.09 & 0.5 & 0.37 & Fit & 27 & 0.87 & -0.9 & 0.49 & Fit \\
\hline 13 & 1.06 & 0.4 & 0.41 & Fit & 6 & 0.78 & -1.2 & 0.56 & Fit \\
\hline 33 & 1.10 & 0.5 & 0.38 & Fit & 15 & 0.80 & -1.0 & 0.47 & Fit \\
\hline 16 & 1.07 & 0.5 & 0.47 & Fit & 5 & 0.74 & -1.5 & 0.53 & Fit \\
\hline 39 & 1.04 & 0.3 & 0.40 & Fit & 45 & 0.66 & -1.1 & 0.36 & Fit \\
\hline 4 & 1.09 & 0.5 & 0.39 & Fit & 18 & 0.78 & -1.6 & 0.55 & Fit \\
\hline 48 & 0.95 & -0.2 & 0.54 & Fit & 9 & 0.77 & -1.8 & 0.61 & Fit \\
\hline 44 & 1.07 & 0.4 & 0.35 & Fit & 3 & 0.67 & -2.4 & 0.61 & Fit \\
\hline 43 & 1.08 & 0.4 & 0.32 & Fit & 17 & 0.69 & -2.0 & 0.50 & Fit \\
\hline 8 & 1.08 & 0.6 & 0.54 & Fit & 7 & 0.62 & -2.5 & 0.59 & Fit \\
\hline
\end{tabular}

Table 5. The results of item difficult of chemistry learning anxiety. 


\begin{tabular}{|l|l|l|l|l|l|}
\hline Item & Difficult index & Category & Item & Difficult index & Category \\
\hline 41 & -1.01 & Very easy & 21 & 0.26 & Medium \\
\hline 24 & -1.07 & Very easy & 48 & 0.24 & Medium \\
\hline 22 & -1.17 & Very easy & 13 & 0.22 & Medium \\
\hline 26 & -1.17 & Very easy & 17 & 0.22 & Medium \\
\hline 35 & -1.37 & Very easy & 12 & 0.08 & Medium \\
\hline 40 & -1.43 & Very easy & 36 & -0.07 & Medium \\
\hline 20 & -1.75 & Very easy & 47 & -0.25 & Medium \\
\hline 23 & -2.33 & Very easy & 16 & -0.36 & Medium \\
\hline 10 & -0.61 & Easy & 30 & -0.36 & Medium \\
\hline 38 & -0.72 & Easy & 3 & -0.37 & Medium \\
\hline 27 & -0.73 & Easy & 28 & 0.94 & Difficult \\
\hline 18 & -0.76 & Easy & 33 & 0.78 & Difficult \\
\hline 11 & -0.77 & Easy & 39 & 0.74 & Difficult \\
\hline 8 & -0.83 & Easy & 15 & 0.72 & Difficult \\
\hline 25 & -0.83 & Easy & 32 & 0.72 & Difficult \\
\hline 34 & -0.89 & Easy & 31 & 0.62 & Difficult \\
\hline 9 & -0.96 & Easy & 1 & 0.54 & Difficult \\
\hline 19 & 0.48 & Medium & 2 & 0.54 & Difficult \\
\hline 4 & 0.45 & Medium & 37 & 3.14 & Very difficult \\
\hline 6 & 0.45 & Medium & 45 & 2.21 & Very difficult \\
\hline 14 & 0.41 & Medium & 44 & 1.45 & Very difficult \\
\hline 5 & 0.39 & Medium & 46 & 1.24 & Very difficult \\
\hline 7 & 0.34 & Medium & 43 & 1.21 & Very difficult \\
\hline 29 & 0.29 & Medium & 42 & 1.13 & Very difficult \\
\hline
\end{tabular}

\subsection{Reliable}

The reliability of an instrument is used to determine whether an item on a device is spread out along a continuum. Reliability results can be seen by paying attention to the Alpha Cronbach value.
According to [22] that the closer Cronbach's alpha coefficient is to 1.0 the greater the internal consistency of the items in the scale. Meanwhile, criteria of Alpha Cronbach value based on [23], if > 0.9 indicates excellent; $>0.8$ indicates good; $>0.7$ indicates acceptable; $>0.6$ indicates questionable; > 0.5 indicates poor and $<0.5$ indicates unacceptable.

Table 6. Statistics of person and item reliable

\begin{tabular}{|l|l|l|l|l|l|l|l|}
\hline \multicolumn{2}{|l|}{ Infit } & Outfit & \multicolumn{2}{l|}{} \\
\hline $\begin{array}{l}\text { Parameter } \\
(\mathrm{N})\end{array}$ & $\begin{array}{l}\text { Mean- } \\
\text { square }\end{array}$ & $\begin{array}{l}\text { Z- } \\
\text { standard }\end{array}$ & $\begin{array}{l}\text { Mean- } \\
\text { square }\end{array}$ & $\begin{array}{l}\text { Z- } \\
\text { standard }\end{array}$ & Separation & Reliable & Category \\
\hline Person(115) & 1.02 & -0.2 & 1.02 & -0.1 & 3.85 & 0.94 & Excellent \\
\hline Items (46) & 1.03 & 0.2 & 1.02 & 0.1 & 6.95 & 0.98 & Excellent \\
\hline
\end{tabular}

Based on Table 6 , the instrument reliable was analyzed according to the person and item analysis. The person reliable value is found 0.94, indicating excellent reliable with a 3.85 separation index while the item reliable value is found 0.98 , indicating excellent reliable with a 6.95 separation index.

\subsection{Information Function}

Information function is a method used to describe an item suitable for measuring the estimated level of ability [24]. Function information is also used to describe the reliable coefficient of the overall test item. Figure 2 showed that the maximum IF value of the CLAS instrument with 48 items found to be 1.071. The function information graph showed that 0.2 and 0.4 which means the statement used produces high information on individuals with a high ability or showed statement with high difficulty.
The initial CLAS consists of 46 items that contain the three aspects. The number of items on each CLAS was well distributed on 13 items on anxiety in the study chemistry aspect, 13 items on anxiety in finishing of chemistry tasks aspect, and 22 items on doing a practicum. The reliable of the person and item is found in the excellent category. The item difficult was well distributed on a very easy, easy, medium, difficult, and very difficult category. 


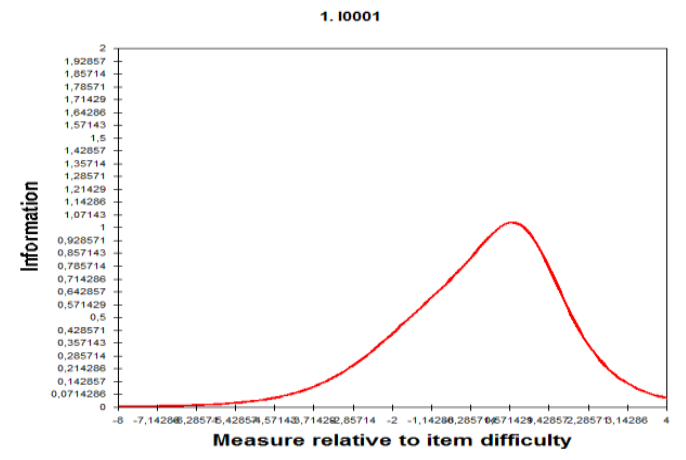

Figure 2 Test information for CLAS

\section{CONCLUSION}

The result of this study showed that CLAS instrument has construct validity. This suggests that the CLAS instrument is the potential to be a useful instrument for researchers and chemistry teachers for measuring the chemistry learning anxiety of students.

\section{ACKNOWLEDGMENT}

I want to thank you for my supervisors dr. Antuni Wiyarsi, teachers Mrs. Martin and students at SMA Negeri 1 Godean and, teachers Mrs. Mekar, Mr. Mashuda, and students at SMA Negeri 1 Sleman, Daerah Istimewa Yogyakarta, Indonesia for their help in collecting data.

\section{REFERENCES}

[1] R.B. Sund, L.W. Trowbridge, Teaching Science by Inquiry in The Secondary School Second Edition, Charles E Merrill Publishing Company, 1979.

[2] G. Sirhan, Learning Difficulties in Chemistry: An Overview, Journal of Turkish Science Education 4(2) (2007) 2-20.

[3] K.S. Taber, Challenging Misconceptions in The Chemistry Classroom: Resources to Support Teachers, Educació Química 4 (2009) 13-20.

DOI: https://doi.org/10.2436/20.2003.02.27

[4] M.M Woldeamnuel, H. Atagana, T. Engida, Students Anxiety towards The Learning of Chemistry in Some Ethiopian Universities, African Journal Chemistry Education 3(2) (2013) 28-38.
[5] E. Kaya, A. Yildirim, Science Anxiety Among Failing Students, Elementary Education Online 13(2) (2014) 518-525.

[6] N.I. Kurbanoglu, A. Akin, The Relationships Between University Students Organic Chemistry Anxiety, Chemistry Attitudes, and Self-efficacy: A Structural Equation Model, African Journal Chemistry Education 4(4) (2012) 347-256.

[7] T.J. Huberty, Test and Performance Anxiety, Principal Leadership 10(1) (2009) 12-16.

[8] N.F. Kamarudin, N.H. Ibrahim, J. Surif, M. Ali, C.A. Talibm N.I. Ismail, Malaysian Science Stream Students Anxiety towards Chemistry at The Secondary School Level, International Recent Technology and Engineering 7(65) (2019) 725-738.

[9] W. Abendorth, F. Friedman, Anxiety Reduction for Beginning Chemistry Students, Journal of Chemical Education 60(1) (1983) 25-26.

[10] R.M. Eddy, Chemophobia in The College Classroom: Extent, Sources, and Student Characteristic, Journal of Chemical Education 77(4) (2000) 514-517. DOI: https://doi.org/10.1021/ed077p514

[11] W.C. McCharty, B.B. Wildanski, Asessment of Chemistry Anxiety in A Two Year College, Journal of Chemical Education 86(12) (2009) 1447-1449.

DOI: https://doi.org/10.1021/ed086p1447

[12] C.S. Huey, Assesment of Chemistry Anxiety Among College Students, Chemistry Education Sustanable 1 (2013) 27-34. DOI: https://doi.org/10.1007/978-94-007-4860-6_3

[13] E. Senocak, M. Baloglu, The Adaptation and Preliminary Psychometric Properties of The Derived Chemistry Anxiety Rating Scale, Chemistry Education Research and Practice 15(4) (2014) 800-806. DOI: https://doi.org/10.1039/c4rp00073k

[14] S.A. Jegede, Students Anxiety Towards The Learning of Chemistry in Some Nigerian Secondary Schools, Educational Research and Review 2(7) (2007) 193-197. DOI: https://doi.org/10.5897/ERR.9000310

[15] C.W. Bowen, Development and Score Validation of A Chemistry Laboratory Anxiety Instrument (CLAI) for College Chemistry Students, Educational and Psychological Measurement 59(1) (1999) 171-185. DOI: https://doi.org/ 10.1177/0013164499591012 
[16] N. Guler, G.K Uyanik, G.T. Teker, Comparison of Classical Test Theory and Item Response Theory in Terms of Item Parameters, European Journal of Research on Education 2(1) (2014) 1-6.

[17] A.S. Beavers, J.W. Lounsbury, J.K. Richards, S.W. Huck, G. Skolits, S.L. Esquivel, Practical Considerations for Using Exploratory Factor in Educational Research, Pratical Assesment, Research and Evaluation 18(1) (2013) 1-13.

[18] R. Brown, Rasch Analysis of the WURSS-21 Dimensional Validation and Assesment of Invariance, Journal of Lung, Pulmonary and Respiratory Research 3(2) (2016) 46-53. DOI: https://doi.org/10.15406/jlpr.2016.03.00076

[19] O.O. Adedoyin, T. Makatobi, Using IRT Psychometric Analysis in Examining the Quality of Junior Certificate Mathematics Multiple Choice Examination Test Items, International Journal of Asian Social Science 3(4) (2013) 992-101.

[20] J.M. Linacre, Local Independence and Residual Covariance: A Study of Olympic Figure Skating Ratings, Journal of Applied Measurement 10(2) (2009) 157-169.

[21] W.J. Boone, J.R. Staver, M.S. Yale, Rasch Analysis in The Human Science, Springer, 2014.

[22] J.A. Gliem, R.R. Gliem, Calculating, interpreting and reporting cronbach's alpha reliability coefficient for likert-type scales, in: Midwest Research-to-Practice Conference in Adult, Continuing, and Community Education, Ohio State University, Columbus, 2003, pp. 82-88.

[23] D. George, P. Mallery, SPSS for Windows Step by Step: A simple Guide and Reference 11.0 Update $4^{\text {th }}$ ed, Boston, 2003.

[24] B.B. Baker, S. Kim, The Basic of Item Response Theory Using R, Springer, 2017 